\title{
AÇÃO SINDICAL BANCÁRIA NO SÉCULO XXI: CONSTRANGIMENTOS E POSSIBILIDADES DO ESPAÇO VIRTUAL
}

\section{BANIKING SECTOR UNIONISM IN THE XXI ${ }^{\text {ST }}$ CENTURY: CONSTRAITS AND POSSIBILITIES OF THE VIRTUAL SPACE}

\author{
Luiza Borges Dulci*
}

\begin{abstract}
RESUMO
A rotina de trabalho nos bancos foi profundamente alterada com a introdução das operações digitais. Restritas às agências e centros de controle nos anos $1970 \mathrm{e}$ 1980, as operações online logo tornaram-se visíveis ao público, por exemplo, com os caixas automáticos, o home e o office banking e, hoje, com a internet e o mobile banking. O conjunto dos trabalhadores bancários se viu diante de desafios-chave. As formas de organização, se em categoria ou setor, e mobilização dos bancários estão sendo repensadas. Além disso, os bancários brasileiros têm procurado se inserir em redes globais de trabalhadores, no âmbito de cada banco e dos setores bancário e de serviços. O papel de internet é crucial neste processo. Ao mesmo tempo em que ela é base dos novos sistemas de processamento e controle dos bancos, dissemina a informação para os trabalhadores, permitindo a atualização de suas pautas e a cooperação internacional.
\end{abstract}

Palavras-chave: Bancários. Tecnologia. Ação sindical.

\begin{abstract}
The work routine at the banks has been deeply altered by the introduction of the digital operations. Restricted to the agencies and control centers in the 1970's and 1980 's, the online operations soon became visible to the public, due to, for example, ATM's, home and office banking and, nowadays, to the internet and mobile banking. That group of workers has, then, seen its category face some key challenges. The forms of organization, if in categories or sector, and mobilization are been rethinked. Beyond that, the Brazilian financial workers have been trying to integrate global networks of labours within specific banks and also within the banking sector and the services sector. The internet assumes a crucial role on the process. At the same time that it is the base of the new processing and control systems of the banks, it disseminate information to the workers, allowing the renewal of their guidelines and the international cooperation.
\end{abstract}

Keywords: Financial sector workers. Technology. Unionism.

"Bacharel em Ciências Economicas - UFMG. Assessora de Juventude do Ministério do Desenvolvimento Agrário (MDA). Mestranda do Programa de Pós-Graduação em Sociologia e Antropologia PPGSA/UFRJ. 


\section{Introdução}

A realidade da automação nos bancos é mundial e está em constante transformação. As mudanças vem alterando a natureza das tarefas executadas; o tipo e o grau de qualificação exigidos dos trabalhadores; seu perfil social, econômico e político; as relações de poder constituídas no interior das instituições financeiras; e os modos de produzir.

Em meados da década de 1990 a internet chegou aos bancos e trouxe modificações importantes não apenas para a rotina de trabalho dos bancários, mas também para a maneira do banco se relacionar com seus clientes. Até o fim daquela década, a internet era tratada apenas como mais um canal de oferta de serviços; contudo, no início dos anos 2000, as intranets dominavam as plataformas internas de comunicação (FONSECA, MEIRELLES e DINIZ, 2010, p. 261). A possibilidade da realização de transações em tempo real acelerou sobremaneira o trabalho bancário. Além disso, o internet e mobile banking são vistos como canais complementares de interação e, para muitos clientes, são a opção prioritária de relacionamento com os bancos. A chegada da internet aos bancos tem posto novos e diferentes desafios para cada trabalhador, para as representações sindicais e para a própria teoria social.

A virtualização do sistema financeiro mundial vem acompanhada do chamado desemprego tecnológico e de crescentes pressões sobre os trabalhadores que permanecem nos bancos. Entretanto, não há dúvidas que muitas das inovações introduzidas vieram a facilitar o trabalho, por exemplo, com a diminuição da quantidade de informações a ser digitada ou transcrita. Também reduziu-se, em parte, as preocupações com os cálculos das compensações e o fechamento dos caixas, que passaram a ser feitos pelos computadores.

O que nos interessa analisar neste artigo é o caráter contraditório do ambiente virtual para o universo bancário. Se por um lado se observa o aumento das cobranças e do controle sobre o trabalho e a redução do custo das transações por meio virtual; por outro lado, a internet fortalece, por exemplo, formas de ação e mobilização internacional dos trabalhadores.

Assim, diante dessas modificações de cunho estrutural, observamos que o movimento sindi- cal bancário, no brasil e no mundo, têm buscado se reinventar na tentativa de contrabalançar as investidas do capital financeiro em direção à crescente racionalização do trabalho nos bancos. A natureza global do fenômeno da automação e da estruturação do sistema bancário impõe a necessidade de estratégias que, da mesma forma, procurem dar respostas globais aos desafios em questão. A proposta deste artigo é analisar como os bancários brasileiros vem formulando estas estratégias e traduzindo-as em esforços de ação e mobilização sindical.

Sabemos contudo, que as experiências globais de troca no mundo do trabalho já são realidade em muitos outros setores da economia. Tanto é assim que há diversos estudos dedicados ao espaço do trabalho nas redes globais de produção (global production networks) (EVANS, 2010; SELWYN, 2012; CUMBERS, NATIVEL e ROUTLEDGE, 2008; dentre outros). Todos eles buscam ressaltar o papel do trabalho no processo de globalização e como os trabalhadores reconfiguram seus movimentos a partir da contextualização global de suas lutas.

Tomamos a categoria bancária como estudo de caso para a análise dos constrangimentos e das possibilidades que as tecnologias da informação e da comunicação colocam aos trabalhadores e aos movimentos sindicais na atualidade.

Cabe observar que os esforços da renovação sindical bancária no Brasil neste novo século tem sido possíveis em função da melhora dos indicadores macroeconômicos e de mercado de trabalho no país. Com a interrupção da tendência de redução do emprego bancário brasileiro, a partir do início dos anos 2000, os trabalhadores puderam ampliar sua agenda e incorporar temas mais amplos, para além da pauta sindical tradicional.

De lá para cá ganharam força as bandeiras por melhores condições e qualidade de vida e, aos poucos, os bancários foram se abrindo a zonas de contato com outras organizações políticas e movimentos sociais. Além disso, seguindo a trajetória de diversas categorias, os bancários brasileiros têm buscado se articular internacionalmente e têm se integrado a redes sindicais com atuação na América Latina e no mundo.

Aconcordância dos fenômenos de ampliação da agenda e fortalecimento das relações de âmbito global corrobora o argumento de Sorj (2003). O autor vê a 
globalização, antes de tudo, como a democratização das sociedades em escala internacional, na medida que promove a criação de um espaço unificado de expectativas de igualdade e abre a possibilidade para a construção de um patamar global de cidadania.

O imperativo da conexão digital é, portanto, visto pelo autor como um "universo que possui tanto o potencial de reconstruir o mundo no sentido de uma maior liberdade e participação social, quanto o de levar ao aprofundamento da desigualdade social e a novas formas de concentração do poder" (SORJ, 2003, p. 14). Nas sessões seguintes analisaremos como esta dialética se coloca para o universo dos trabalhadores bancários.

Este artigo possui três seções, além desta Introdução e das Considerações Finais. A primeira delas apresenta um breve histórico das mudanças tecnológicas vivenciadas pelos bancos desde a década de 1960, com destaque para as inovações mais recentes, posteriores à chegada da internet. Analisamos ainda as implicações destas mudanças para a rotina de trabalho nos bancos e os impactos sobre os trabalhadores. A segunda seção introduz o conceito de co-determinação do capital e do trabalho no processo de desenvolvimento capitalista. Argumentamos que as estratégias econômicas e tecnológicas dos bancos são influenciadas pelas ações dos trabalhadores. Isto é, ainda que de maneira desigual, capital e trabalho são ambos agentes do processo de desenvolvimento e podem potencializar sua força a depender das estratégias de atuação adotadas. Finalmente, na terceira seção analisamos as estratégias dos bancários brasileiros, como elas têm buscado se reinventar e qual o papel do espaço virtual neste processo.

\section{As transformações nos bancos e a rotina de trabalho bancário}

Há duas sortes de questões que devem ser consideradas quando tratamos da estruturação e da modernização do sistema bancário brasileiro a partir da segunda metade do século XX. A primeira delas consiste na Reforma Bancária e a segunda diz respeito às novas tecnologias introduzidas nos bancos.

A Reforma Bancária (Lei n. 4595/1964) foi, desde fins dos anos 1940, longamente debatida no Congresso Nacional e, quando aprovada, veio a consolidar nosso sistema bancário em âmbito efeti- vamente nacional. A menção à Reforma se justifica pelo fato de que, ainda hoje, esta é a legislação que regula o funcionamento dos bancos brasileiros, a despeito das várias resoluções e mudanças introduzidas desde então. Naquele momento foram criados o Banco Central do Brasil e o Conselho Monetário Nacional (CMN), foi estabelecida a regulamentação sobre a participação de bancos estrangeiros no país e sobre a relação dos bancos com empresas de outros setores da economia, dentre outras medidas (MINELLA, 1988).

Nas duas décadas seguintes, o setor bancário nacional passou por um período de uniformização das normas, ao mesmo tempo em que aumentou sua inserção internacional e caminhou em direção à uma maior concentração e centralização financeira, ou seja, tornou-se mais oligopolizado.

A respeito da segunda questão, a das as mudanças tecnológicas, o destaque para a inovação que deu início a uma grande transformação na atividade bancária fica com os chamados Centros de Processamento de Dados (CPDs), que chegaram aos bancos na década de 1960. Os CPDs marcaram o início da fragmentação e da racionalização do trabalho nos bancos, na medida em que as informações passaram a ser apreendidas - colecionadas, classificadas, combinadas e tabuladas - pelas próprias máquinas.

Até o início dos anos 1980 a automação bancária consistiu na difusão do sistema online, que interconectou as diversas agências dos bancos em tempo real. Logo mais, vieram os caixas eletrônicos de auto-atendimento e os cartões magnéticos. Surgiu ainda a possibilidade de realização de algumas operações via telefone. Foi também nessa época, mais especificamente em 1979, que os bancos tiveram a primeira experiência de compartilhamento de estruturas, com o "Banco 24 horas", fruto da parceria entre os bancos Unibanco, Bamerindus e Nacional (FONSECA, MEIRELLES e DINIZ, 2010).

Já no final dos anos 1980 e início dos anos 1990, a automatização extrapolou os limites espaciais das agências, e as transferências eletrônicas dos dados passaram a ser feitas também a partir de residências e escritórios, com os chamados home e office banking. A partir dos anos 1980, portanto, as transformações tornaram-se visíveis e mesmo disponíveis aos clientes dos bancos. De lá para cá, os investimentos em inovação têm se voltado ao desenvolvimento de 
canais de comunicação entre o banco e seus clientes, assim como à realização de operações financeiras fora do que se entende por espaço bancário por excelência, as agências.

Os anos 1990 são identificados, dentre outros aspectos, pela difusão generalizada dos caixas automáticos, dentro e fora das agências bancárias. Nesse período, diversas inovações de hardware, software e de redes de comunicação de dados foram introduzidas nas agências e nos departamentos administrativos dos bancos. A partir da segunda metade da década, uma das prioridades adotadas foi a diversificação do mix de produtos e serviços financeiros ofertados. E em 1996 tiveram início as primeiras transações bancárias pela internet - canal que deslanchou na década seguinte.

Os anos 2000 e 2010 parecem ter consolidado um modelo de banco que já se delineava na década de 1990, a saber, um banco com múltiplos canais de atendimento e interação com os clientes. Além da reconfiguração do papel da internet para o funcionamento dos bancos na atualidade, "a revolução silenciosa" pela qual passaram as áreas de tecnologia dos bancos nos anos 2000, envolveu o desenvolvimento da noção de "TI ${ }^{1}$ alinhada a negócios".

Esta ideia nasceu da percepção dos bancos de que os canais eletrônicos de atendimento, tanto na agência, através dos caixas eletrônicos, quanto na internet, poderiam servir também como postos de venda de produtos. Assim, cada vez mais, os bancários assemelham-se a vendedores, que possuem cotas audaciosas de comercialização de produtos e serviços financeiros.

Vale lembrar que as instituições bancárias atuais são, em sua maioria, a cabeça de grandes holdings, isto é, de conglomerados financeiros que abarcam, além dos bancos, empresas de seguros, de títulos de capitalização, de previdência complementar, etc (SOARES, 2013).

Os canais virtuais da internet e do mobile banking adéquam-se muito bem aos propósitos atuais de comercialização dos bancos. Sanches (2012) aponta que, entre 2003 e 2010, o número de transações anuais realizadas via internet no Brasil passou de 2,6 bilhões para 12,8 bilhões. No ano de 2013, enquanto as transações bancárias realizadas nas agências somaram 3,9 bilhões, os caixas automáti-

\footnotetext{
${ }^{1}$ TI: Tecnologias da informação.
}

cos registraram 9,4 bilhões, o internet banking, 16,6 bilhões e o mobile banking, 2,3 bilhões de transações (FEBRABAN, 2013).

De fato, a ampliação dos canais virtuais como internet e mobile banking é extremamente atrativa para os bancos, na medida em que reduz o custo unitário das transações. A Pesquisa CIAB Febraban de 2012 mostrou que o canal virtual reduziu em $17,5 \%$ o custo unitário nos últimos cinco anos (20072011 ) e gerou um aumento de $73,4 \%$ no volume das transações no mesmo período (FEBRABAN, 2012).

A chegada das máquinas e dos softwares alterou não apenas a própria arquitetura das agências bancárias, como também a distribuição dos trabalhadores dentro delas. Postos de trabalho foram extintos, outros foram criados, mas sempre em proporção inferior, resultando em diminuição no número de bancários no país. Assim, "dos cerca de 1 milhão de bancários existentes no Brasil em 1985, restavam apenas algo em torno de 400 mil no ano 2000" (SOARES, 2013, p. 20).

Com relação aos salários, os dados divulgados pelo DIEESE registram aumento real de 13,9\% entre 2004 e 2011, apesar da média salarial da categoria ter crescido apenas $3,6 \%$ no período - fato que se deve justamente à substituição de funcionários mais antigos por novos ${ }^{2}$.

Outra inovação que veio a distanciar ainda mais os clientes dos bancos tem a ver com os correspondentes bancários ${ }^{3}$. Estes são estabelecimentos como lotéricas, supermercados, correios e vários outros, que, conectados online com os bancos, prestam serviços de recebimentos de contas, saques, transferências, etc. A capilaridade dos correspondentes bancários têm contribuído para ampliar a taxa de bancarização brasileira, isto é, o grau de acesso da população aos serviços bancáriofinanceiros.

Contudo, devido à forma como vem ocorrendo esta inclusão bancária, os bancários a apelidaram de "bancarização sem bancários", uma vez que os

\footnotetext{
${ }^{2}$ Informações disponíveis no portal da Agência Brasil (EBC): http://agenciabrasil.ebc.com.br/noticia/2012-07-22/dieese-mesmo-crescendo-nos-ultimos-dez-anos-emprego-no-setor-bancario-e-70-do-total-ha-duas-decadas, consultadas no dia 24 de outubro de 2013.

${ }^{3}$ Idealizado em 1992 por uma rede de farmácias com sede em Fortaleza, o modelo dos correspondentes bancários tornou-se possível a partir de alterações na regulação bancária, introduzidas pelo CMN em 1999 e em 2003 , e logo se difundiu por todo o Brasil, especialmente nas regiões com menor taxa de bancarização (JAYO e DINIZ, 2009).
} 
serviços são prestados por funcionários do comércio ou terceirizados, que não têm o conhecimento necessário para a realização de tais atividades e não recebem os mesmos salários ou têm assegurados os direitos conquistados pela categoria bancária.

O debate das terceirizações nos bancos assume cada vez maior centralidade para a categoria, uma vez que atinge parcela significativa dos bancários brasileiros. A terceirização nos bancos avançou não apenas em número, mas também na quantidade de cargos e áreas de atuação. Para além dos serviços gerais, como vigilância e limpeza, nos anos 1990, os terceirizados passaram a atuar nos setores de compensação, recursos humanos, treinamento de pesquisa, manutenção, teleatendimento, dentre outros. Oliveira destaca inclusive, que grande parte dos trabalhadores bancários demitidos no processo de reestruturação do setor continuou exercendo as mesmas atividades, porém contratados por empresas terceirizadoras sob condições de trabalho, remuneração e proteção social inferiores ou inexistentes (OLIVEIRA, 2009, p. 13).

Ao sair do banco e passar para empresas terceirizadas, os trabalhadores incorrem em perdas significativas. Perdem direitos conquistados pela categoria e deixam de pertencer ao sindicato dos bancários, o que lhes confere ainda mais vulnerabilidade e insegurança no emprego.

Sobre os bancários que ainda permanecem nos bancos vigora o aumento do controle do trabalho e a cobrança por metas de produtividade. Em seu estudo sobre os trabalhadores de escritório ${ }^{4}$, Braverman (1977) analisou detalhadamente como a automação simplifica e rotiniza as tarefas, tornando o trabalho muito mais suscetível de cômputo e medida. De fato, com a automação, o tempo para a execução das tarefas tornou-se pré-determinado e mais controlável, levando ao aumento das cobranças nos bancos. "Ao longo da jornada de trabalho podem ser disponibilizados relatórios completos e detalhados da atividade produtiva, seja por pessoa ou por locais de trabalho incluindo aqueles em que os serviços estão terceirizados" (SANCHES, 2012, p. 16). Segundo a autora, tais relatórios são utilizados como referência tanto

\footnotetext{
${ }^{4}$ A classificação de trabalhadores de escritório de Braverman inclui as ocupações de contador, secretária, estenógrafo, caixa, caixa de banco, arquivista, telefonista, mecanógrafo, serviço do pessoal, estafeta, recepcionista, almoxarife, datilógrafo e semelhantes (Braverman, 1977).
}

para premiações quanto para a exposição negativa daqueles trabalhadores que obtiveram produção inferior ao esperado.

Em função das metas de produtividade ou de venda de produtos e serviços, alguns bancários "procuram vender produtos dos bancos fora do horário de trabalho para familiares, amigos ou conhecidos. Muitos chegam a comprar os produtos que precisam vender até completar sua meta" (SOARES, 2013, p. $62)$.

As formas de exprimir as cobranças também se alteraram. Celulares, e-mails e outros meios de comunicação vem sendo utilizados com frequencia. Este fenômeno aumenta forçosamente a disponibilidade dos funcionários, "fazendo com que o tempo de trabalho "invada" o de não-trabalho"" (SOARES, 2013, p. 65). Por conta disso, multiplicaram-se os registros de doenças físicas e psíquicas e aos poucos esse tema passou a fazer parte da agenda sindical da categoria. $\mathrm{O}$ autor constatou que as reclamações de tensão, estresse, ansiedade e nervosismo são generalizadas entre os bancários, que, segundo a Previdência Social, é uma das categorias mais atingidas por casos de adoecimentos no trabalho.

Somente em 2009, foram registrados 7.717 casos de empregados do setor bancário que adquiriram LER ${ }^{5}$ no exercício de suas funções de trabalho. Em 2010, 1.200 bancários em média foram afastados a cada mês por auxílio-doença concedido pelo $\mathrm{INSS}^{6}$, metade dos quais devido à contração de LER ou de transtornos mentais. Os transtornos mentais vão desde uma pequena depressão até tentativa de suicídio, passando por transtorno obsessivo compulsivo, transtorno bipolar, síndrome do pânico, perda de juízo, etc (SOARES, 2013, p. 58).

Além disso, os próprios clientes aparecem como outra fonte de cobrança cuja posição é cada vez mais destacada. Para La Garza (2011) a participação dos consumidores, usuários e detentores de direitos no processo produtivo é direta, pois o produto não se gera sem sua presença em um momento chave da produção: o consumo. Esta condição altera não apenas as relações sociais, mas principalmente as relações de poder no processo produtivo.

\footnotetext{
${ }^{5}$ LER: lesão por esforços repetitivos.

${ }^{6}$ INSS: Instituto Nacional do Seguro Social.
} 
Conforme analisa o autor, o controle do cliente começa como pressão simbólica para a realização do trabalho no espaço e tempo esperados, assim como na qualidade por ele requerida. Entretanto, as formas de controle extrapolam a dimensão simbólica e incluem formas de regulação formal - como normas da empresa, código do consumidor e outras leis - e informal - que apela para a ética, combinada às emoções do trabalhador, incluindo aspectos como atenção, cortesia e "bons costumes".

Em suma, todas essas mudanças relatadas tiveram efeito sobre o cotidiano da atividade bancária, alteraram os ritmos do trabalho e as funções desempenhadas pelos trabalhadores. A variável tecnológica, entretanto, não foi a única fonte das transformações analisadas. Parcela significativa das mudanças vivenciadas pelos bancários foi motivada por alterações na legislação bancária, nas políticas macroeconômicas e na regulação do mercado de trabalho.

O setor bancário dos anos 1990 vivenciou movimentos de concentração e centralização bancária, ao mesmo tempo em que facilitou a entrada de bancos estrangeiros no país. Estas medidas estavam alinhadas à orientação político-econômica do período, que visava abrir a economia brasileira ao mercado internacional e atrair investimentos e empresas estrangeiras com o intuito de atualizar nossa estrutura produtiva, tornando-a mais competitiva.

Programas como o Proer e o Proes ${ }^{7}$ impulsionaram o aumento do desemprego na categoria bancária, juntamente com as inovações tecnológicas. Contribuíram ainda para o aumento do desemprego as medidas recessivas que orientaram as políticas econômicas, caracterizadas, dentre outros aspectos, pela redução do investimento estatal, pelos baixos salários e pelos baixos volumes de crédito concedidos.

Esta tendência concentradora permanece até os dias de hoje entre os bancos do país. Exemplo disso são as fusões entre os bancos Real e Santander; e Itaú e Unibanco, ambas em 2008. Entretanto, na década de 2000, houve uma reversão das políticas que regem os bancos públicos brasileiros. De lá para cá eles tornaram-se atores importantes do modelo de desenvolvimento adotado no país. Bancos de desen-

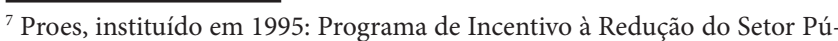
blico Estadual na Atividade Bancária. Proer, instituído em 1996: Programa de Estímulo à Reestruturação e ao Fortalecimento do Sistema Financeiro Nacional.
}

volvimento, como o Banco Nacional de Desenvolvimento Econômico e Social (BNDES) e o Banco do Nordeste, recuperaram suas funções de concessão de crédito ao setor produtivo, dando ênfase ao componente regional.

Outra variável fundamental para nossa análise é a estrutura de oportunidades políticas. Para Tarrow (apud Alonso, 2009), ela corresponde "às dimensões formais e informais do ambiente político, à abertura de novos canais para expressão de reivindicações de grupos sociais de fora da polity" (ALONSO, 2009, p. 55). Em outras palavras, a estrutura de oportunidades políticas responde pelo grau de democratização e de funcionalidade dos canais de cidadania e de diálogo na sociedade.

Nos anos 1990 as regulações do mercado de trabalho e as decisões sobre a legislação trabalhista foram claramente desfavoráveis aos trabalhadores, o que implicou o estreitamento da estrutura de oportunidades políticas. Pessanha e Morel (1999) apontam que naquele período o tradicional modelo legislado das relações de trabalho no Brasil se viu, por vezes, ameaçado por práticas do modelo negociado.

O poder legislativo aprovou leis que flexibilizaram as jornadas de trabalho. Autorizou o banco de horas; o trabalho em tempo parcial - com correspondente redução de salário, encargos e benefícios; e o contrato por tempo determinado, medidas essas que implicaram a retirada de direitos dos trabalhadores e reduziram seu poder de barganha frente aos patrões. O poder executivo assumiu posições claras de não tolerância a greves, congelou os salários do funcionalismo público e negligenciou políticas de aumento do salário mínimo. Em suma, o ambiente político e socioeconômico da década foi pouco favorável à contestações sociais e à participação popular e de forte pressão sobre os trabalhadores.

Nos anos 2000 o cenário pouco afeito à práticas democráticas e estagnado ou recessivo do ponto de vista econômico foi alterado. Ainda que haja discordâncias nas análises acadêmicas e políticas sobre o grau de reversão do cenário anterior, os dados relativos ao crescimento do número de greves e à participação de expoentes da classe trabalhadora no poder executivo e legislativo revelam mudanças nos rumos e nas práticas políticas do país. E como afirma Alonso (2009), quando a estrutura de oportunidades políticas é favorável, "grupos insatisfeitos organizam-se 
para expressar suas reivindicações na arena pública" (ALONSO, 2009, p. 55).

$\mathrm{O}$ aspecto das greves é fundamental, na medida em que está diretamente relacionado com o poder de barganha dos trabalhadores. Nos anos 1990, estas tornaram-se inviáveis. No setor público não eram toleradas pelo governo, que não negociava e punia os grevistas; - no privado, o medo das demissões, naturalmente, recuava os trabalhadores. A nova estrutura de oportunidades políticas, conformada a partir de 2004, permitiu a retomada das greves e a conquista de novos direitos. As greves dos bancários a partir de então foram anuais e a categoria deixou para trás a agenda defensiva dos anos 1990 em função de outra mais propositiva e ampliada nos anos 2000.

Ao trazer este conjunto de variáveis políticas e econômicas para a análise pretendemos mostrar que as variações no nível do emprego e dos salários são resultado de combinações de variáveis sociais, políticas e econômicas. As informações contidas na tabela a seguir mostram como até mesmo as mudanças tecnológicas - que se apresentam como estruturais e têm alcance global - são impactadas e mediadas pelos contextos político e sócioeconômico do país.

\begin{tabular}{|c|c|c|c|}
\hline \multicolumn{4}{|c|}{ Relação entre o emprego e os investimentos em tecnologia no setor bancário nacional (1990-2010) } \\
\hline Ano & Número de bancários & Variação do emprego em relação ao ano anterior & Investimento em tecnologia ( $\mathrm{R} \$$ bilhões) \\
\hline 1990 & 732.217 & 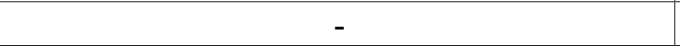 & 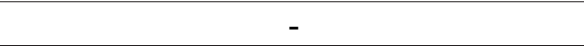 \\
\hline 1991 & 679.931 & $-7,41$ & - \\
\hline 1992 & 632.392 & $-6,99$ & - \\
\hline 1993 & 655.211 & 3,36 & - \\
\hline 1994 & 571.252 & $-12,81$ & - \\
\hline 1995 & 558.692 & $-2,2$ & - \\
\hline 1996 & 483.165 & $-13,52$ & 1,5 \\
\hline 1997 & 446.830 & $-7,52$ & 1,8 \\
\hline 1998 & 426.442 & $-4,56$ & 2,1 \\
\hline 1999 & 392.869 & $-7,87$ & 2,5 \\
\hline 2000 & 402.425 & 2,43 & 2,9 \\
\hline 2001 & 393.140 & $-2,31$ & 3,1 \\
\hline 2002 & 398.183 & 1,26 & 3,5 \\
\hline 2003 & 399.183 & 0,27 & 4,2 \\
\hline 2004 & 405.073 & 1,48 & 4,2 \\
\hline 2005 & 420.036 & 3,69 & 4,6 \\
\hline 2006 & 422.219 & 0,52 & 5,3 \\
\hline 2007 & 445.828 & 5,59 & 5,8 \\
\hline 2008 & 459.494 & 3,07 & 6,4 \\
\hline 2009 & 462.164 & 0,58 & 4,9 \\
\hline 2010 & 483.097 & 4,53 & 6,6 \\
\hline 2010/1996 & $0,1 \%$ & - & $340 \%$ \\
\hline
\end{tabular}

Fonte: Ministério do Trabalho e Emprego - RAIS

Elaboração: Dieese Subseção SESE - Sindicato dos Bancáios de São Paulo, Osasco e Região.

Tabela combinada, retirada do texto de Sanches, 2012

Como se vê, nos anos 2000, variáveis como o aumento da população bancarizada, a melhora dos indicadores macroeconômicos e de mercado de trabalho e o aumento das regulações no setor financeiro e trabalhista foram decisivas para permitir a recuperação dos patamares de emprego de meados dos anos 1990, paralelamente aos crescentes investimentos em tecnologia.
Este fenômeno nos leva às análises de um conjunto de autores que mostram como os rumos tomados pelo capital e pelo trabalho influenciam-se mutuamente e produzem efeitos capazes de alterar as decisões um do outro. É o que trataremos na seção seguinte.

Capital e trabalho: co-determinantes orgânicos do desenvolvimento capitalista 
Nesta seção introduzimos o conceito de codeterminação orgânica do trabalho e do capital no processo de desenvolvimento capitalista. Argumentamos, que ambos influem nas decisões de investimento das empresas, ainda que não na mesma proporção. Isto é, há espaço para a agência dos trabalhadores e tal espaço pode ser potencializado a depender das estratégias sindicais adotadas e da eficácia de sua implementação.

Os efeitos negativos sobre o emprego e sobre a organização do trabalho advindos das tecnologias microeletrônicas - na forma como foram concebidas e implementadas - atingiram diversos setores da economia. Contudo, os impactos observados não foram homogêneos e variaram no tempo e de acordo com as categorias de trabalho.

Falabella (1988) adota a premissa de que os efeitos das tecnologias são mediados por três variáveis-chave: i) a conduta do capital; ii) a força sindical propriamente dita; e iii) a projeção política dos sindicatos. A conduta do capital compreende as taxas de investimento e o ritmo de introdução das inovações. A força sindical abrange os graus de organização e de unidade da classe trabalhadora. E, finalmente, a projeção política inclui a força dos partidos pró-sindicais na estrutura partidária e sua presença no Estado; o grau de abertura política do governo ao diálogo e à negociação com os trabalhadores; e a legitimidade social dos sindicatos ${ }^{8}$.

Em seu estudo, Falabella trata de exemplos europeus (Suécia, Noruega, Alemanha, Inglaterra e Itália) e mostra que quanto mais espaço os trabalhadores têm nos governos e nos parlamentos, maior é sua força para conseguir implementar acordos trabalhistas avançados ou até mesmo legislações nacionais que os favoreçam. Em linhas gerais, sua argumentação atenta às oportunidades e aos limites da capacidade que os trabalhadores e suas organizações têm de influenciar as decisões e o planejamento das empresas.

Podemos ir mais longe e supor que as variáveis-chave do autor são também mediadores válidos para outros conjuntos de mudanças. Isto é, além dos efeitos da tecnologia, contextos políticos e regulações do mercado de trabalho podem ser atravessados

${ }^{8}$ Percebe-se uma semelhança entre o que Falabella chama de projeção politica dos sindicatos e a estrutura de oportunidades politicas, de Tarrow. pela conduta do capital; pela força sindical e pela projeção política dos sindicatos.

Em reflexão semelhante, também sobre o contexto sindical europeu, Hyman (2001) propõe que a força dos sindicatos é tanto maior quanto mais eles se organizam em torno de um triângulo cujos vértices são o mercado, a classe e a sociedade. $O$ vértice do mercado compreende as lutas no mercado de trabalho, por salário e emprego. As questões relativas à classe incluem as greves e as lutas por direitos; por fim, no vértice da sociedade estão as questões relativas às condições e à qualidade de vida. Segundo o autor, a negligência de um dos três vértices acaba por enfraquecer as representações sindicais.

Ambos os autores defendem, portanto, que os sindicatos tenham três frentes concomitantes de atuação. Por estarem interligadas, o fortalecimento ou enfraquecimento de uma das frentes impacta no mesmo sentido as demais.

Para Selwyn (2012) o repertório de ação sindical deve ser entendido não apenas como estratégia de barganha salarial, mas, em sentido mais profundo, como co-constituinte das relações de produção e distribuição da riqueza. Isto é, trabalho e capital devem ser encarados como co-determinantes orgânicos do desenvolvimento capitalista, com capacidade para influir nas decisões de investimento e, portanto, no processo de acumulação.

Como propõe De Sardan (2005), os atores envolvidos nos processos de desenvolvimento, sejam os vinculados ao capital, sejam os vinculados ao trabalho, têm recursos de poder - desiguais e desequilibrados -, mas não são, nunca ou quase nunca, destituídos da capacidade de alterar e influenciar as configurações sociais.

As inovações tecnológicas, dentre elas a internet, emergem como processos sociais em disputa, que ampliam o horizonte de ação tanto do capital quanto do trabalho. As oportunidades para um ou para outro não estão em pé de igualdade, mas têm potencial para fortalecer ambos os lados da equação social.

Ao construir um panorama das análises sobre redes globais de produção, Santos (2011) traz uma reflexão importante acerca das variáveis que devem compor uma "análise que pretenda captar a complexidade da integração funcional dispersa que caracteriza a globalização econômica" (SANTOS, 
2011, p. 133). Para o autor, este tipo de análise deve incorporar à discussão dos fenômenos estritamente econômicos uma compreensão dos fenômenos economicamente relevantes, isto é, dos eventos que, ao incorporar agentes e relações não econômicos, produzem efeitos importantes no âmbito da economia (SANTOS, 2011, p.133).

As ações sindicais, ou as investidas do trabalho, podem ser compreendidas sob este prisma. Isto é, são eventos que, a princípio, não se identificam como econômicos, mas que têm impactos e consequências relevantes para o cenário econômico, devendo ser levados em conta na lógica que rege as decisões de investimento e planejamento das empresas.

Ao mesmo tempo em que as estratégias e os espaços de atuação do capital se alteram e se atualizam, o trabalho despende esforços no sentido de se reinventar, na tentativa de contrabalançar ou, quem sabe, até mesmo reverter as investidas do capital. $\mathrm{Na}$ próxima seção do trabalho veremos como os bancários têm enfrentado estes desafios, com ênfase nas experiências de organização sindical globais.

\section{Novas estratégias sindicais, na teoria e na prática}

A despeito dos diversos direitos conquistados pelos bancários brasileiros ao longo de seus mais de 80 anos de lutas, o que se observa é que as bandeiras que defendem a co-participação sindical nas decisões sobre inovação e tecnologia nos bancos não são bem recebidas pelos banqueiros.

De fato, ao tratar das tecnologias e buscar participar das decisões a seu respeito, os bancários demandam participar da construção de seu futuro, do futuro dos bancos e do próprio modelo de desenvolvimento do país. Ao problematizar as inovações, eles tocam em questões como as formas de organização e de controle do trabalho e evidenciam que muitas escolhas técnicas são concebidas com o fim de impor ordens sociais específicas.

Segundo Segnini (1998), as atenções sindicais iniciais a respeito da tecnologia vieram já no início dos anos 1980. As primeiras preocupações centravam-se nas demissões, no treinamento adequado às novas funções e na participação dos trabalhadores nos lucros e demais vantagens, em caso de aumento da produtividade. Aos poucos vieram cláusulas re- ferentes às pausas de descanso para digitadores, aos horários dos caixas e às comissões paritárias para discutir as tecnologias. Nas Convenções Coletivas de Trabalho (CCTs) atuais ainda vigoram as reivindicações de adicionais de insalubridade e periculosidade, e o controle de produção dos digitadores - que estabelece um número máximo de toques permitidos por dia.

Ao longo dos anos 1980 e 1990 a luta em torno dos direitos relativos à saúde do trabalhador foi ganhando corpo e novos sintomas e doenças passaram a ser objeto de atenção dos bancários. $\mathrm{Na}$ década de 1990, as lutas da saúde resultaram em três direitos inscritos nas CCTs: i) a complementação salarial para afastados por doença/acidentes e verba de requalificação profissional; ii) a criação da comissão permanente de saúde, ambas em 1997; e iii) a Implantação do Programa de Prevenção, Tratamento e Readaptação de LER/DORT ${ }^{9}$, em 1998.

De lá para cá os bancários não conseguiram avançar muito na pauta da tecnologia, e menos ainda nas tentativas de democratizá-la. Oliveira (2003) analisa as CCTs de diversas categorias profissionais nos anos 1990 e aponta os bancários, juntamente com os metalúrgicos, como os trabalhadores que mais sofreram as consequencias dos processos de reestruturação produtiva. E segundo seu estudo, no caso dos bancários, "houve uma clara recusa do empresariado em negociar a introdução de inovações tecnológicas, que já vinham ocorrendo desde os anos 1980" (OLIVEIRA, 2003, p. 286).

Para além das resistências e ações no âmbito das inovações tecnológicas, os bancários têm buscado atualizar e ampliar sua agenda de reivindicações e suas bandeiras de luta. Dos anos 2000 para cá, em função da abertura de novas oportunidades políticas no país, vem ganhando força as lutas por melhores condições de trabalho e por mais qualidade de vida. Parte destas novas bandeiras procura dialogar e atrair a solidariedade e o apoio de outros grupos sociais.

Para exemplificar, podemos mencionar a seção "Diversidade" das CCTs, que incluiu na negociação de 2009/2010 a cláusula "Extensão de vantagem às relações homoafetivas”. Esta cláusula assegura que as vantagens da Convenção Coletiva, aplicáveis aos cônjuges dos empregados, sejam extensivas aos

\footnotetext{
${ }^{9}$ LER (Lesão por esforços repetitivos). DORT (Distúrbios Osteomusculares Relacionados ao Trabalho).
} 
casos em que a união decorra de relação homoafetiva estável, devidamente comprovada.

Concomitantemente à atualização da agenda, os bancários têm buscado renovar seu repertório sindical de maneira geral. Tilly (2010) emprega o conceito de repertório em seus estudos sobre movimentos sociais. O conceito refere-se ao conjunto variável de atividades e de formas de ação política - aos procedimentos, táticas e estratégias - empregados pelos movimentos sociais no contencioso da política e nos processos de reivindicação coletiva.

Nos últimos anos, os bancários têm incorporado novas discussões e temáticas ao seu antigo conjunto de pautas e de lutas. Para além das paralisações e greves, ações de protestos e negociação com os bancos, seu repertório atual inclui, por exemplo, o ajuizamento de ações na Justiça do Trabalho, o acionamento do Ministério Público do Trabalho, a atuaçao junto a sindicatos internacionais e a reivindicação de normas e de termos da Organização Internacional do Trabalho.

No que diz respeito às mudanças nas formas de abordagem sindical, observa-se que os sindicatos têm se apropriado das novas tecnologias para ampliar seu contato com setores variados da sociedade, bem como para fins organizativos próprios. "Veículos como a internet (site e TVweb, twitter), torpedos, DVDs, têm sido utilizados no relacionamento dos sindicatos com a base, na tentativa de contorno da efemeridade dos tempos e da falta de interesse nas formas de participação tradicionais" (SANCHES, 2012, p. 28).

Mais um traço inovador emergiu na greve nacional bancária de 2013. Nessa ocasião, os sindicatos dos bancários de todo o Brasil e a Confederação Nacional dos Trabalhadores do Ramo Financeiro (Contraf) buscaram incorporar novas linguagens e novas formas de aproximação a categoria, assim como com a sociedade. Para tanto, fizeram uso de expressões e símbolos típicos do universo vitual, à exemplo dos cartazes com a chamada "\#vempraluta Bancário"10.

Outras duas mudanças no repertório de atuação merecem destaque, na medida em que ressignificam

\footnotetext{
${ }^{10} \mathrm{O}$ esforço de comunicação com os jovens é fundamental para a categoria bancária, uma vez que $31,6 \%$ dos trabalhadores bancários tinham até 30 anos em 2009. Os trabalhadores entre 30 e 50 anos somavam $58,6 \%$ e os acima de 50 anos, apenas 9,7\%, segundo o Relatório Anual da Febraban, de 2009.
}

antigas estratégias sindicais: as campanhas contra o assédio moral e as greves. Ao denunciarem publicamente as práticas de assédio moral que sofrem com frequencia no trabalho, os bancários levam os bancos a intensificarem suas áreas de marketing e a investirem na marca do banco, a fim de contrabalançar e tentar reduzir o impacto das denúncias entre os clientes.

A respeito das greves, Sanches (2012) chama a atenção para o fato de que elas, cada vez mais, se localizam nos centros administrativos e tecnológicos dos bancos. Ao mesmo tempo em que as paralisações nesses locais provocam grande impacto na rede bancária, distanciam os grevistas das agências e dos clientes, diminuindo as pressões diretas sentidas pelos bancários.

As greves têm também assumido novos significados. Tidas tradicionalmente como instrumentos de pressão sobre os banqueiros, eram quase que exclusivamente dirigidas a eles. Mais recentemente, no entanto, elas têm incluído ações orientadas aos clientes e à sociedade de modo geral. Mais do que pressionar os bancos, os bancários têm buscado sensibilizar e informar os clientes sobre o ambiente e as condições de trabalho a que estão submetidos.

Ainda sobre os sentidos de reconfiguração de práticas sindicais, a mudança da Confederação Nacional dos Bancários (CNB) para a Confederação Nacional dos Trabalhadores do Ramo Financeiro, em 2006, é emblemática. Sua motivação foi incorporar à representação sindical parcela dos trabalhadores do setor financeiro - caso dos milhares de terceirizados - que não eram reconhecidos como bancários. Com a criação da Contraf, a categoria ampliou suas pautas e passou a dialogar com trabalhadores em condições muito distintas daquelas vivenciadas pelos bancários tradicionais. Não se trata de negar as especificidades da categoria bancária e descartar conquistas que são fruto de décadas de luta. Entretanto, de fato, estes trabalhadores são hoje parte de holdings que envolvem diversas outras categorias e há a necessidade de se pensar, do ponto de vista sindical, o setor bancário como um todo.

Esses e outros exemplos indicam que, no mínimo, as pressões do lado do trabalho impõem ao capital a necessidade de justificar, quando não de mudar efetivamente sua forma de organização, para que o processo de acumulação tenha continuidade. 
Podemos nos questionar, portanto, como os trabalhadores podem potencializar sua capacidade de agência. O desafio é grande, mas têm sido buscadas alternativas de superar os obstáculos colocados. Novas formas de organização e comunicação entre bancários têm surgido e novos caminhos estão sendo trilhados com este objetivo.

O papel da internet é destacado e merece a atenção dos analistas sociais, na medida em que traz, ao mesmo tempo, constrangimentos e possibilidades para as lutas sindicais. É o que argumenta Sorj (2003) a respeito das tecnologias da informação e da comunicação, que atuam como

Um campo privilegiado para se compreender a dialética entre igualdade e desigualdade, pois refere-se a um universo que possui tanto o potencial de reconstruir o mundo no sentido de uma maior liberdade e participação social quanto o de levar ao aprofundamento da disegualdade social e a novas formas de concentração do poder (SORJ, 2003, p. 14).

Em seguida vamos analisar com mais atenção a atuação e a mobilização internaicional na qual se inserem os bancários brasileiros, destacando a importância das tecnologias da informação e da comunicação para estas experiências recentes de organização dos trabalhadores.

A adesão dos bancários brasileiros a instâncias de luta internacionais, no plano regional e global, é recente, mas já tem dado frutos. Com as articulações internacionais cresce o potencial de pressão sobre os bancos, assim como são potencializadas a força dos trabalhadores e as possibilidades de troca de experiências de luta.

A Contraf, antes CNB, filiou-se ao Union Network International (UNI) Global Finance ${ }^{11}$ ainda na década de 1990 e os laços internacionais vêm crescendo desde então, especialmente na América Latina.

Para Castro (2011) foram dois os fatores que pesaram para a adesão ao UNI: i) o crescimento da automação bancária e o interesse em tomar contato com as formas que os demais sindicatos mundo afora empregavam para enfrentar tais problemas; e

\footnotetext{
${ }^{11}$ Criada, em 1999, da fusão da Federação Internacional dos Trabalhadores de Serviços (FIET), da CI (Comunication International) e da Federação Internacional dos Gráficos.
}

ii) a abertura comercial brasileira, associada também aos primeiros impulsos de criação do Mercosul, fato que reforçava a necessidade de estreitar laços com o sindicalismo regional e internacional.

Em 2004, o Brasil sediou, em Curitiba, uma reunião que decidiu pela criação da Coordenadoria Sindical Internacional do HSBC, com a secretaria ficando sob a responsabilidade dos bancários brasileiros. Integraram a reunião, além dos representantes da CNB/CUT e Conteg/CGT do Brasil, a Federación de Trabajadores Bancarios (Fetraban/CUT - Paraguay), Asociación de Empleados Bancarios de Uruguay (AEBU/PITCNT), Asociación La Bancaria de Argentina (CGT), Confederación Bancaria de Chile (CSTEBA/CUT).

Em 2011, outro encontro, desta vez em São Paulo, patrocinado pela UNI e pela Contraf, lançou as campanhas pela negociação de Acordos Marco Globais $^{12}$ com os bancos Santander e HSBC, em favor da defesa de direitos iguais para os trabalhadores desses bancos em todo o mundo. O encontro reuniu dirigentes sindicais bancários de 19 países da Europa, Ásia e Américas (CASTRO, 2011).

No mesmo ano, o Banco do Brasil também assinou o Acordo Marco com a Union Network Americas. $\mathrm{O}$ acordo inclui normas de não discriminação de gênero e raça, o reconhecimento da liberdade sindical e da negociação coletiva, o combate ao assédio sexual e moral, a abolição de todas as formas de trabalho escravo e infantil, dentre outras. Há ainda cláusulas que assumem o compromisso de respeitar as Declarações de Direitos Humanos da ONU, a Declaração do Rio de Janeiro sobre Meio Ambiente e Desenvolvimento e a Convenção das Nações Unidas contra a Corrupção (CASTRO, 2011).

Como podemos ver, os trabalhadores têm buscado usufruir das novas tecnologias em benefício de suas organizações. Quanto maior é o conteúdo ao qual eles têm acesso, melhor é sua capacidade de argumentação. Este fenômeno foi alvo da atenção de Hyman (2002) e Evans (2010).

\footnotetext{
12 "O Acordo Marco é um modelo mais recente de negociação e tem sido um substitutivo da negociação coletiva internacional (praticada praticamente apenas no interior da União Européia). Em geral é um compromisso assumido por uma empresa multinacional perante uma organização de trabalhadores - muitas vezes uma Federação Sindical Internacional - FSI - em benefício dos seus empregados em qualquer lugar do mundo. Isso pressupõe o reconhecimento de alguns direitos tais como: sindicalização, negociação coletiva, igualdade de oportunidades, fim do trabalho infantil e do trabalho escravo" (CASTRO, 2011, p. 5).
} 
Ambos os autores apostam que as inovações nas telecomunicações podem atuar na democratização do espaço sindical e torná-lo mais interativo e menos hierárquico. Além disso, essas inovações podem ser empregadas na construção de novas formas de solidariedade, na medida em que trascendem ou reduzem as barreiras geográficas, culturais e até linguísticas.

Evans (2010) destaca ainda a importância da mobilização a nível global para contestações locais e nacionais. $\mathrm{O}$ autor enfatiza como o aprofundamento do neoliberalismo vem criando oportunidades de organização dos trabalhadores em todo o mundo.

As possibilidades de intercâmbio trazidas pela internet e pelas facilidades de transporte da atualidade permitem a troca de experiências e expertises não apenas dos trabalhadores entre si, mas também com outros movimentos sociais. Este fenômeno fortalece tanto os laços de classe, quanto as relações dos trabalhadores com os demais grupos sociais, ou seja, com a sociedade.

Esta abertura de zonas de contato e troca de experiências entre trabalhadores e movimentos sociais é, para Santos (2002), um trabalho de tradução entre práticas, reivindicações e aspirações trabalhistas e os objetivos de cidadania, de proteção ao meio ambiente e de anti-discriminação contra mulheres, minorias étnicas etc, levantados por outros movimentos ou organizações. Segundo o autor "tais traduções têm vindo a transformar lentamente o movimento operário e os outros movimentos sociais ao mesmo tempo em que têm tornado possíveis constelações de lutas que há uns anos seriam impensáveis" (SANTOS, 2002, p. 270).

\section{Considerações finais}

As mudanças vivenciadas pela categoria bancária, no Brasil e no mundo, em função da chegada das tecnologias microeletrônicas alteraram sobremaneira, e à força, as estratégias sindicais. Nos anos 1990, os bancários viram sua categoria reduzir drasticamente em número e privilegiaram a luta pelo emprego e pelos salários. A partir dos anos 2000, no Brasil, a abertura de novas possibilidades políticas permitiu a ampliação das pautas sindicais, assim como a ampliação das formas de atuação.
A internet é uma variável-chave deste processo de transformações. Nos anos 1990 e início dos anos 2000, ela era encarada como mais um canal de atendimento e relacionamento dos bancos com seus clientes. No entanto, ao fim da primeira década do século XXI, sua dimensão era outra. A internet é hoje a base dos sistemas de desenvolvimento, operação e controle dos bancos. São justamente as operações digitais que garantem o caráter ubíquo e imediato das transações bancárias do nosso tempo.

As consequencias para o sistema bancário, que inclui banqueiros, trabalhadores e clientes, foram diversas e, em certa medida, contraditórias. Houve redução dos custos dos bancos e ganhos de agilidade e eficiência. Os clientes viram seus canais de relacionamento com os bancos se multiplicarem, e hoje o núméro de clientes com mobile banking no Brasil já ultrapassava os 3 milhões em 2011, enquanto as contas de internet bankings já somavam 41,9 milhões (Febraban, 2011). Mas a redução no número de bancários e, principalmente, de bancários disponíveis ao atendimento ao público - caso dos caixas de banco - trouxe desconforto para parte dos clientes e muitos desafios à categoria. Esta se vê hoje submetida, por exemplo, à cobranças por metas de produtividade que levam, com frequencia, a adoecimentos e até suicídio de trabalhadores.

A categoria viu ainda sua principal forma de luta, a greve, ser enfraquecida pelas novas tecnologias. Isto é, com as possibilidades de acesso ao banco por caixas automáticos, pelo computador e pelo celular, o impacto das greves é fortemente atenuado.

Tudo isso traz desafios para cada trabalhador, para as representações sindicais e para a própria teoria social.

A categoria bancária vem buscando formas de contornar os novos desafios, aproveitando também as possibilidades trazidas pela internet. Fazem parte dessa tentativa de atualização sindical bancária a disseminação de informações dos bancos para clientes e trabalhadores; a pulverização de canais de contato entre a base e a direção sindical; a inserção internacional nas redes sindicais globais, seja por empresa (banco), seja nos sindicatos bancários e do setor de serviços em geral, para citar alguns exemplos.

A revitalização sindical é, sem dúvidas, um processo de aprendizado e, nesse sentido, também passa pelo “desaprender" de velhas rotinas e tradições. 
No caso dos bancários, como vimos, é crescente a diversificação do perfil dos trabalhadores. Isso implica entender que unidade sindical ou unidade na luta difere da noção de uniformidade na classe. A heterogeneidade presente na categoria demanda o uso de novos vocabulários, capazes de dialogar como uma base cada vez mais plural, assim como a troca de experiências e estratégias com movimentos sociais e bancários mundo afora.

\section{Referências Bibliográficas}

ALONSO, Angela. As teorias dos movimentos sociais: um balanço do debate. Lua Nova, São Paulo, 76: 49-86, 2009.

BRAVERMAN, Harry. Trabalho e capital monopolista: A degradação do trabalho no século XX. Rio de Janeiro: Zahar, 1977.

CASTRO, Maria Silvia. Ação sindical internacional no setor bancário, 2011 Disponível no portal do Centro de Pesquisas 28 de Agosto. Acesso em 27 de março de 2014. http://28deagosto.webnode.com/artigos/.

CUMBERS, Andy, NATIVEL, Corinne e ROUTLEDGE, Paul. Labour agency and union positionalities in global production networks. Journal of Economic Geography 8; pp. 369-387, 2008.

De SARDAN, Jean-Pierre Olivier. Anthropology and Development. London: Zed Books, 2005.

EVANS, Peter. Is it labor's turn to globalize? Twenty-first century opportunities and strategic responses. Global Labour Journal. v. 1: Iss: 3, pp. 352-379. 2010

http://digitalcommons.mcmaster.ca/vol1/iss $3 / 3$ Acesso em 2 de abril de 2014.

FALABELLA, Gonzalo. Microeletrônica e sindicatos: a experiência europeia. In: SCHIMITZ, Hubert e CARVALHO, Ruy de Quadros (Orgs.). Automação, competitividade e trabalho: A experiência internacional. São Paulo: Hucitec, 1988.

FEBRABAN, Pesquisa Febraban de Tecnologia Bancária, 2012. http://www.febraban.org.br/7Rof7SWg6qmyvwJcFw F7I0aSDf9jyV/sitefebraban/PesquisaFebrabanTecBanc\%E1 ria2012.pdf. Acesso em 23 de março de 2014.

FEBRABAN, Relatório Anual, 2009. http://www. febraban.org.br/7Rof7SWg6qmyvwJcFwF7I0aSDf9jyV/ sitefebraban/Febraban_completo.pdf. Acesso em 13 de abril de 2014.

FEBRABAN, Relatório Anual, 2011. http://www. febraban.org.br/7Rof7SWg6qmyvwJcFwF7I0aSDf9jyV/ sitefebraban/Febraban_RA2011_30_08.pdf. Acesso em 05 de julho de 2014.
FONSECA Carlos Eduardo Corrêa da; MEIRELLES, Fernando de Souza; e DINIZ, Eduardo. Tecnologia bancária no Brasil: Uma história de conquistas, uma visão de futuro. São Paulo: FGV, 2010.

HYMAN, Richard. The future of unions. Just Labour. v. 1, pp. 7-15, 2002. http://www.justlabour.yorku.ca/volume1/ pdfs/j1_hyman.pdf Acesso em 20 de maio de 2014.

Understanding European trade unionism: Between market, class and society. Londres: SAGE Publications, 2001. Parcialmente disponível em http://books.google. at $/$ books? $\mathrm{id}=\mathrm{pSsbDgKhSr} 4 \mathrm{C} \&$ printsec $=$ frontcover $\& \mathrm{dq}$ $=$ Understanding + European + trade + unionism: + between + market,+ class + and + society $\& \mathrm{hl}=$ de $\& \mathrm{sa}=\mathrm{X} \& \mathrm{ei}=\mathrm{O} 0 \mathrm{Wn}$ U9jgA6fNsATmkIDYBA\&ved $=0$ CB8Q6AEwAA\# $=0$ nepage $\& \mathrm{q}=$ Understanding $\% 20$ European $\% 20$ trade $\% 20$ unionism $\% 3 \mathrm{~A} \% 20$ between $\% 20$ market $\% 2 \mathrm{C} \% 20$ class $\% 20$ and\%20society\&f=false. Acesso em 15 de maio de 2014.

JAYO, Martin; DINIZ, Eduardo. Correspondentes Bancários como Canal de Distribuição de Serviços Financeiros: o Papel dos "Gestores de Rede". Anais da XV Americas Conference on Information Systems. São Francisco (EUA), 2009. Acesso em 13 de março de 2014. http://www.ictformicrofinance.org/ sites/default/files/13.pdf

LA GARZA, Enrique. Trabajo no clásico, organización y acción colectiva. Cidade do México: Plaza e Valdés, 2011.

MINELLA, Ary. Banqueiros - Organização e poder político no Brasil. Rio de Janeiro: Espaço e Tempo/ANPOCS, 1988.

OLIVEIRA, Marco Antônio de. Tendências recentes das negociações coletivas no Brasil. In: SANTANA, Marco Aurélio e RAMALHO, José Ricardo (Orgs.). Além da fábrica: Trabalhadores, sindicatos e a nova questão social. São Paulo: Boitempo, 2003.

OLIVEIRA, Ricardo. "Desterceirização" e a intensificação do trabalho: idas e vindas da flexibilidade no setor bancário estatal. Rio de Janeiro: UFRJ/ IFCS, 2009.

PESSANHA, Elina; MOREL, Regina. Mudanças Recentes no Modelo de Relações de Trabalho no Brasil e Novo Sindicalismo. In: Rodrigues, Iram (Org.). Novo Sindicalismo 20 Anos Depois. Rio de Janeiro: Vozes, 1999.

SANCHES, Ana Tércia. Dimensões da difusão tecnológica no setor bancário e a nova divisão do trabalho. 2012 Disponível no portal do Centro de Pesquisas 28 de Agosto. Acesso em 31 de março de 2014. http://28deagosto.webnode. com/artigos/.

SANTOS, Boaventura de Sousa. Para uma sociologia das ausências e uma sociologia das emergências. Revista Crítica de Ciências Sociais, n. 63, pp. 237-280, 2002.

SANTOS, Rodrigo. Redes de produção globais (RPGs): contribuições conceituais para a pesquisa em ciências sociais. Revista Pós Ciências Sociais, v.8, n.15, pp.127-141. 2011. 
SEGNINI, Liliana. Mulheres no trabalho bancário. São Paulo: Edusp, 1998.

SELWYN, Ben. Beyond firm-centrism: reintegrating labour and capitalism into global commodity chain analysis. Journal of Economic Geography. v. 12. Iss: 1. 2012

SOARES, José Luiz. Radiografia da Mobilização Bancária. Rio de Janeiro: UFRJ/IFCS, 2013.

SORJ, Bernardo.Brasil@povo.com: A luta contra a desigualdade na Sociedade da Informação. Rio de Janeiro: Jorge Zahar, 2003.

TILLY, Charles. Movimentos sociais como politica. Revista Brasileira de Ciência Política, no 3 . Brasília, janeiro-julho, pp. 133-160, 2010.

Recebido em: 15-01-2015

Aceito em: 17-04-2015 